\title{
Self, free will and the place of brain in the legal domain
}

\author{
Chetan Sinha \\ OP Jindal Global University
}

Sonipat

\begin{abstract}
The movements to understand the free will and choice, which is empirically apparent to the observer, is contested by brain science. Further explorations about intentions, reasons along with deception have brought the meaning of self and agency under re-examination. However, a triangulated picture with other scientific evidence may make the picture clear. The aim will be to ponder upon the free will, law and brain determinism. Since brain studies are emerging as an important interdisciplinary domain such as law and psychology, it may be interesting for readers to have a knowledge about the common-sense understanding of brain functioning and how it connects to the philosophical problems of solipsism and knowledge of other minds, freedom of actions, purpose and the will. Not apart from this, the conceptual errors and further debates speculated by the legal theorists and social scientists in the integration of law and neuroscience which has empirical, practical and ethical implications will be highlighted
\end{abstract}

That our action should be judged by our intentions-Michel De Montaigne

How does law cater to the dignity of people thinking and action? It usually relies on evidence, available morality codes, knowledge and ability to control and act. Here we will critically deal with the idea of passivity, in the sense, how we passively receive the knowledge and become a passive being, which is associated with the determinism ${ }^{1}$. This is no doubt contrary to the idea of will which demands that we filter what we don't want into our social cognitive boundaries. So, the proponents of free will also entertain the idea of control and the meaning of responsibility diverge into two aspects of thinking about the self, such as controlling action which is contrary to the general moral periphery of society and doing something which is regarded as virtuous. In the first part one is a responsible person who utilizes control and in the

\footnotetext{
${ }^{1}$ Was John Locke's passive recipients also empirical beings and any of their conscious act was not the matter of will but their ignorance? Preprint by Dr. Chetan Sinha, OP Jindal Global University, Sonipat

Email: sinchetan@gmail.com,csinha@jgu.edu.in
} 
second case it is a person who is responsible for his good acts. Contrary to this responsibility also caters to the persons intentional doing or creating a conscious situation not catering to the ethical and moral standards appropriated by the social conventions, a general rule in which we as members of society are socialized.

\section{Free will and choice}

The view about the passivity of receptions of external stimuli which is considered to shape the personality, selves and identity, however, is what the person is and the person's view of the society. In fact, this view is about the person as part of society, whether he/she is going by the conventional societal rules or not because in both the cases it is the societal stimuli which shaped the person. In this case, wrong or right actions seem passive to the core and any verbal format to reconstruct that passivity into active language may be illusions of free will. This was well described by Billig (2019) when he was discussing the differences in the Locke's atomist and Shaftesbury's common sense and holistic view of perception. If all our acts and language is passive, then our identity is also passive and fully ascribed. This process of becoming passive is happening in the passively designed environment where all the agents are passive, the stimuli which we perceive, the action of others, social relations seem to be a passive natural process uncontrollably happening like the Earth moving on its orbit and doesn't have any will to cross it.

The idea of deciding pessimism, passivity, determinism, destiny is dealt within the particular way of observation. However, to deal with the human passivity, societal interactions and uncritical examination of actions under the broader idea that everything is permanent, unchanging and passive flow and bombardment of stimuli over one another, one has to ascertain a permanent design under which the world is operating, which is not possible yet. If everything is so much concretely designed that human don't have any control over the process, but still, we see differences in the human individual/social process across different social groups. We can infer from the various social observations and the experiences phenomenologically verified within ourselves, that the stimulus which we passively receive within our knowledge system and outside our awareness, when analysed are all stimuli one is socialized, artificial and as a matter of human social cognition. For example, our view of the winter season and activities to protect ourselves from the cold we engage in behaviour considered to be appropriate for survival. To act for survival is not passive but active 
engagement with the environment. What about those who don't have a proper means to protect themselves from the winter as higher income groups do? This is not a passive recipient of the uncontrollable stimuli but a socially created condition under which one is unable to control his situation. To control and not to control is a humanity problem and not the natural bombardment of stimuli. Many of the current psychologist influenced by the modernity and empiricism speculated the link between behaviour and brain, which to some extent taken as active regulator of human thoughts and actions, so this is also one kind of determinism where human don't have much control, just like humans are also seems to be a passive recipient of stimuli operating around them. But we have to be clear that humans chose out of so many stimuli operating around them, maybe this type of choice making is also considered as determined by human nature. In the words of Eric Fromm (1964),

"the freedom of choice where determinism or indeterminism is involved is always the freedom to choose the better as against the worse-and better or worse always is understood in reference to the basic moral question of life-that between progressing or regressing, between love and hate, between independence and dependence. Freedom is nothing other than the capacity to follow the voice of reason, of health, of well-being, of conscience, against the voices of irrational passions" (P. 130).

If we talk about those stimuli, we need to understand the perspective which impels us to think that we are passive, active or both. The perspectives are never individual as it seems but they are means for socially representing something collectively sensed and conscious. Freedom of will is a self-conscious and dignified movement of the being. Dignified in the sense that the person is not passively receiving and regulated by the uncontrolled brain, but the person has conscious and active control over both the bombardment of external and internal stimuli arising out of the external and internal environment (e.g., brain). In social psychology, dignity is a matter of how much the being is self-conscious of his/her social presence. For example, how much any person from the oppressed group became aware and self-conscious to participate in the collective effort for emancipation. Also due to reception of various social stimuli in a different way the person makes him/her a product of social only and his/her subjectivity is nothing but objectivity regardless of the debate on private experiences or qualia. The paradox between social and person has been extensively debated and tried to resolve it through the eliminativists and reductivists epistemologies. But this is also from the observers' viewpoint to infer about the cause of the person's action, legal domain heavily relies on these epistemologies but fails to account for the human responsibility as a social responsibility. So, privacy is public 
and attenuated in the persons in varieties of ways, but then why do people differ across the culture? Because of variations in the levels of receptions and the person's engagement in the society, we see the differences. This still doesn't resolve the paradox and we have to be a kind of compatibilist who acknowledge the biological difference in the person and their reception of stimuli shaping their way adapting to the sociocultural and empirical world. Law as a matter of systematic belief and conventions about the mechanism of objects in interrelationship. These interrelationships may be about the movement of celestial objects, movement of atoms in some solid thing or human interaction in a class system. Every domain has its law in some conventions. Law supposedly embedded in the activities, only some language describes its presence. The legal domain is about human relationships but it is not algorithmic but conventionally heuristic where legal agents systematically correspond to the existing discourses. For example, a defendant lawyer trying to prove his client's innocence through the mitigating evidences from neuroscience (e.g., Langleben \& Moriarty, 2013). So here evidence has to be discussed within the established systems of legal domain. Evidence corresponds to the human way of understanding the social world and not any other organism. Even the artificial intelligence designed to help humans corresponds to human way of computations rather than any other organism.

The idea of evidence about the knowledge and intentionality caters to the public and societal level understanding of the person rather than the qualitative and undecipherable myths. Since inner un-explorable and language less experience, as assumed by few philosophers, may lead to the false illusion of hidden and unaccountable experiences, together with the impression that the person with true feeling of oppression is manipulating through his/her language about his/her experience. Much of the time our narration of our qualitative experiences is congruent and true but taken as gibberish and false. Language not always diverts from the felt experiences but denotes to the best of the possibility of one's subjectivity. Jacquette (2009) emphasized that "where there is action, there is an intrinsic intending of an objective or state of affairs, even if it is only a basic body action or mental act" (P. 256). What law count is action which is considered to be intrinsically intentional but the only question is about the consciousness and self-consciousness which are the marker of dignity and liberty of mind, and the reality of brain which seems to matter beyond the control of the person (e.g., some of the scholars like Fuster (2013) took the brain stance especially the prefrontal cortex as a precursor to the person liberty) (see also Pribram, 1973). 
Freedom of action carries the intention, like free speech is intended but carries the thought along with it. The empiricist passive recipients are also actors and they claim themselves to be thinking beings. They simultaneously resolve the paradox of person and social through actions and thinking. Sometimes, the intrinsic intentions are countered or carried forward through the action cum thoughts, as in the case of a prospective criminal who in his intended action is controlled through opposite action or inaction by his simultaneous thoughts about the consequences of the criminal acts. The commune of humans has different dynamics from the commune of other animals lower on the phylogenetic scale. The animals' actions on the basis of some observable stimuli, for example attacking on prey or mating behaviour can be considered as species typical behaviour, but according to the human standards, they are not morally responsible despite their being in some rudimentary conscious state of mind. According to Jacquette (2009), "even if animals are rudimentarily self-conscious agents, they are not necessarily capable of the right sort of self-conscious agency with the right sort of control over what they do to make them moral agents" (P. 263). The standards of right and wrong are more implied to humans as they are the progenitor of moral standards and through the folk psychological understanding infer about the possibility of difference between the animal and human of being conscious agents. However, animals also observed to be sacrificing, are compassionate and they also have grievance, reducing them generally as rudimentarily selfconscious agents is a simplified view out of the human limited understanding. As local language or foreign language written in a simple way corresponds to reality and connects with the audience more gracefully, so the idea of morality, responsibility and consciousness will connect with the people in a very popular way. Any technical language which is not in the conscious discourse of the people takes time in becoming part of the discursive self. The paradox which we resolve through our attributions of self and others is very much the popular form rather than the actual technical display of knowledge. Most of the time this popular understanding of others' action is taken as freely chosen rather than some destined or determined form of action. Deterministic attribution comes much later in a post-hoc manner and that too is not devoid of stereotypical worldview of a person belonging to different groups. However, with the active engagement of people or experts from various domains may clarify the situation of the person as an uncontrollable or consciously chosen one.

\section{Free will and law: Reject it or accept it?}


Does the animal go into finding the cause? Do animals have free will? Is crying based on free will? Does a cockroach have the same understanding of the moon as we have? If yes, then still reality matters more for the actors of experiences, then the dominant human community contemplating these questions. Though, if we observe these kinds of questions are minority questions limited to some individuals, free will notion is also limited and whatever boundary is drawn from time to time is normal and ostensibly for the human domain. Pertaining to the above questions it is very difficult to say about animals whether they look for the cause or understand nature in the same way as we humans. Humans also have differences in perceiving the causes and their impression about the possible choices they possess. There are many instances where understanding the cause behind social dominance was actively countered through the movements and activism. In some view, holding onto the restricted and ascribed categories of social dominance is determinism, whereas activism is a matter of free will, in fact, a group free will in a collective context to move from stagnant categories to the new categories. In many of the decolonizing attempts, people from the oppressed group shifted their identity and affiliation from the clutches of the oppressor to the new identity. Since these changes are empirical and observable under the given assumptions about free will, they fulfil the property of human beings, being active rather than passive. But that activity of mind, soul, body and brain (as they are prioritized in legal circles) in whatever capacity operates and is limited by those sociocultural-physical worlds and as they shift or have been critically resisted changes the boundary of human existence and interaction patterns. So, when people resist taking for granted things which are banal, the value of free will and dignity of mind makes its presence. Law values those criticalities, it is not deterministic, it is structured and seems natural to the human constitutions and nature. Sometimes lawmaker intentions matter in the interpretation of any situation, showing law is as systematic, worldly and coveted. Legal domain is limited by its domain as it never talks about something which is destined and metaphysical but it limits to the moral actions, intentions and responsibility. Scientific evidence is also interpreted and they are systematic but their thrust on the public seems to carry more weight. Questioning science, in any way, looks absurd and bolstering, and in no way a rational field like legal domain is going to underscore them.

Under the specificities of law, all humans are legal agents and their ability to choose is universally accepted. Even in the case of mental disorders which is generally used in the legal domain as insanity, as seen through the revised categories of mental disorders (e.g. DSM, ICD, RDoC; see Zachar \& Kendler, 2017), people are observed to make choices. Out of these choices 
some are within the boundaries of normal behaviour and some are not, and that too varies within the different classifications of mental diseases. In one way we find these classifications of mental diseases adding more to the problem of intentionality and mens rea, as every time the rise of mental disease categories, though there were many mental diseases that were removed from the conventional criteria of psychiatrists (e.g. Homosexuality, Draptomania etc), creates new debate about the consciousness and intention about one's action. Mental disease seems to be unending and the rise of interdisciplinary research has created new debates and amendments to the understanding of normal and abnormal. That line which divided normal from the abnormal seems to be more blurred than the earlier times, and hence the people's clarity about moral responsibility. Free will of the actor in the view of an observer is intact and causes are more within the person who seems to be responsible for the actions. Psychologists cited examples, where self and the others are situated in the attributive language, where the other is more responsible than the self and the causes highlighted are proximal and within the persons' intentionality. Identification of causes in the uncontrollable neural firings of the brain paradoxically moderate the role of intentions. How we look at the freedom of persons' action and how much one was responsible for the actions is inferred through the behavioural observation of the person which directly links to the intentions. However, it is the legal domain which makes the boundary more permeable to go beyond these perceived immediate causes and allows for further exploring into uncontrollable aspects of the personality. Though still this a matter of inter-subjectivity among the legal agents where consensus is attained either through the uncritical admissibility of preferred evidences, such as DNA analysis, fingerprints, witnesses, fMRI or adopting the critical and dialogical approach to understand the responsibility and the nature of rehabilitation.

Free will is an important component of the human life where the mind has the potential to be dignified, expressive, understanding of the environments, though some of the perspectives in the psychopathology indicated the suppression of free will to the social structural contexts which gets its expression in some other format, either conforming and adapting to the norms or through some criminal acts. Free will can be bound with the social restrictions, as it happened through the religious regulations, cultural markers and the state interventions. These restrictions inadvertently shape the norms and the general understanding of group morality. The complete hijacking of one's independent free will by the collective consciousness indicates the passivity of the human mind, however, the changes that humans bring to society is based on the assumption that nothing will happen if humans don't act. So, the action whether 
collectively influenced or the individual's struggles to come out of the role of being a passive recipient is a marker of free will. Consciously controlling the inner desire or expressing it are the examples of free will but when any expression of desire is non normative and consistently expressed without self-control in the restricted environment, it is not free will but uncontrollable expression of publicly undesirable behaviour. Since, law is a publicly appropriated domain of control and deterrence, the legal agents who are observed to lack control on their desires are restricted from the free movement in society. The problem with the legal agent who knows what they did and about the nature of their action as right or wrong is considered to be a freely willed action and legal domain looks for the possibility of recidivism or improvement to its standard. Societal specifications and standards also matters as it regulates the control and expression of desires. When dominant societal norms become controlling in the expression of one's proclivities or practicing of one's culture, the free will suppressed takes the new shape in its expression like a river which never stops flowing wherever it finds its way despite the barriers imposed. The notion that we are not free agents (e.g. Gazzaniga, 2011) denotes our passivity of mind and on the other hand limiting to law we are wilfully responsible for our actions puts more weight on legal assumptions.

Freedom is both a liberation and decolonization of self from the toxic and foreign self, stereotypes, and dominant values. It is also about losing or giving one's space for others, like the integration of all value systems in a democratic space. The effort has been made to help people get out from the globalization of brain sciences to clear the forest of confusions surrounding the meaning of free will as will of the brain rather than the will of the person who has a brain. The form of neuro-essentialism which has overtaken the diverse meaning of free will into a singularized form is a new kind of colonization (see also Rose, 2000; Pickersgill, 2013). The development of free will can be seen from the historical, cultural, conceptual or indigenous perspective where it is something in the activity of the person and as a marker of potential or endowment to express its intentions, however linking potentiality to act or express to passivity seems to be a category error (e.g. Ryle, 1949) as it is not clear how passivity embedded the external stimuli and how it gets transformed by the person while expressing. In other words, how a person associates various stimuli, assembles it and comes out with new meaning. Since, society symbolizes conventions, moral rules, structure and group processes why a person thinks and acts differently and not exactly produces what he/she receives. The amalgamation of neurosciences to the law has changed or modified the periphery of the meaning of free will. Why does any shift in the mainstream languages matter and change the 
idea and perception? The definition of free will from time primordial has undergone many perspectival revisions, and with science its definition is becoming subsumed as a deterministic endeavour. That is the same as a liberal determinist who believes in the irresponsible action of the person with a responsible brain (see Herstein, Sifferd \& Fagam, 2018). The notion of reasons-responsiveness and the responsible brain are not two distinct ways of understanding actions and intention but they set on the same platform. The action of the person is judged in a context where the meaning of consciousness seems to be constructed. For example, the action of child and adult in an indigenous culture and in modern culture seems to vary in proposition to the socialization and way of contextual understanding of the family and broader ecology.

\section{The social life of brain and free will}

Sociologist of neuroscience (e.g., Pickersgill, 2013) discussed the normative dimensions of neuroscience which is impacting the law and other fields like the military and giving an objective view to the notions of free will. Though legal scholars expressed their scepticism for taking over of the legal domain by neurosciences, as Berlin (1999) noted that infinity increase of knowledge increases rationality and so the power and freedom but that doesn't make one infinitely free (P. 179). Legal domain believes in the mental content and mental states to determine the responsibility and the intentions, which are the sources of free will. Being in the state of mind to accurately reach out one's knowledge structure may make the person strong enough to be rational but the progenitors of neuroscience will be shying to call it a free will. Free will is not limited to the conscious act but it is also a matter of acts which is done in a taken for granted format where the person is habituated to control or express the behaviour. This habituation in thinking and behaving creates the situation of intentions which is further interpreted as consciousness. The effort of neuroscientists to convince the legal domain that these acts and intentions are conscious is dominantly aided with the brain imaging techniques.

Law is not that interested in the descriptions and mechanisms of the brain as it is interested in the identification of cause of act and whether that cause is within the cognitive reach of the person or not. However, apart from the brain imaging indicators of causal relationship there are human behavioural markers appropriated and understood in the human community and to some extent is seen in other animals' communities. For example, expression 
of happiness, humiliation and dehumanization is well understood in the human community and these states of mind are directed towards some external sources, like, conducive behaviour directed towards the recipient to make them happy or otherwise. So becoming happy or otherwise is observed to be connected to the sources and stimuli outside the individual bringing shifts in the idea of free will more extrinsically driven rather than intrinsic. This phenomenon is observed to be in pain also where an individual becomes the victim of pain, though there are controversies in helping behaviour and altruism theories that people or animals consciously go for pain to help others. However, the social psychologists and gene scientists may go either for social determinism or gene make-up causing one to help his/her group members or others as a form of deterministic influence. Free will then if analysed scientifically somewhere situate into the deterministic stance where it is all mechanism through which an individual acts leaving little reason for individuals' ability to renounce what he/ she has learned or go beyond the general understanding of mechanism. This again causes dilemmas and paradoxical thinking where what is taken as free will is a well-designed mechanism. The paradox of this kind was illustrated by Gazzaniga (2012) as "We are personally responsible agents and are to be held accountable for our actions, even though we live in a determined universe" (P. 2). Pertaining to this statement let us take an example of riots happening in the name of morality, that is, killing or dehumanizing people from different groups as a moral act from the part of ingroup members who consider themselves as powerful and culturally superior.

According to the determinist worldview, morality is universal and is embedded in the brain through an essentialist program of some grand design which causes our behaviour. In that case, legal domain will go by the dominant determinists' discourse, as societal moral construction forms the structure of law and may be the acts of riots justified if seen from those dominant societal morality discourses. However, the legal domain is a matter of cultural context where there are different laws for the same event (e.g. abortion laws of Ireland different from India) and in whatever form it ideally enabling justice. Conversely, as it is just not the society and law connection but there is a triangular connection among the societal moral values, science (or popular science) and the regulatory body, the general understanding of law through the media and everyday discourses feedback the system (e.g., De, 2018). Thus, the intention and the act of killing prejudiced outgroup members or doing riots in the name of free will and facing riot as a victim defines this whole bastion of free will as a politically driven linguistic category which creates the situation of freely acting or passively facing individuals. In both the cases neuroscientists assume the brain activation to the act of the person provided the presence 
of outside cues demanding the immediate act. Even the passive recipient of the external dominance can be interpreted as a matter of free will to receive the pain. The angle of neuroscience is to substantiate the existing legal proceedings but it is simply identifying any atomist cause to the complexity of human acts and will. The agenda of the legal domain is to substantiate free will and not to deny it in any way. Even the arrhythmic and unintentional behaviour is judged under the periphery of free will as it is determined or not due to any uncontrollable mental and environmental circumstances.

Rule of law is a conventional form of discursive practices in some federal space where normative influence adds further to the psychology of free will and in no way, it is a neutral as prominently seen in the neuroscientific assertions. Mechanistic world is then non evaluative world as per the neuroscientific research but we evaluate and judge, which capture the comparative contexts where laws are discussed and amended. The neutrality of humans and the illusion of free will is as difficult to imbibe in our consciousness as it is difficult to leave the destiny behind the public life. However, it is the prevalent discursive practices which also creates critique and debate to look beyond the group think correcting the blind spot. Baxi (2007) looked for both the avenues of the rule of law where dignity, empowerment, resilience and independence together with the good governance ${ }^{2}$. The protection of fundamental right, judicial review, and authentic form of surveillance matters to the court to keep a check on the societal norms which sometimes becomes contrary to the individual right to express and psychological ownership. The rise of neuro-essentialism giving impetus to neuro-justice is one form of neurosurveillance happening with the aid of technologically advanced techniques which has shaped the meaning of consciousness and phenomenology. If everything is surveillance based and dependent on the technology which picturizes the biological system in terms of firing nerves and situatedness of organs, the free will then symbolize the individual body only.

Free will then seems like an embodied form of cognition which is situated in the bodily self but this duality of body and mind was asserted by René Descartes where he affirmed that 'except our own thoughts, there is nothing absolutely in our power ...' ${ }^{3}$. It may also imply that except the thought nothing is in our power, even our own body. Body extends and changes (or

\footnotetext{
${ }^{2}$ Baxi, U. (2007). The rule of law in India. Sur, 3, São Paulo. http://socialsciences.scielo.org/scielo.php?script=sci_arttext\&pid=S180664452007000100001

${ }^{3}$ Rene Descartes, discourse on the method and the mediations 26 (John Veitch trans Cosimo, 2008) Preprint by Dr. Chetan Sinha, OP Jindal Global University, Sonipat Email: sinchetan@gmail.com, csinha@jgu.edu.in
} 
deteriorates) with time and all effort made by some to stop or slow down those changes after some time, is a will of the person. People try to resolve those dualities either by engaging or disengaging with something which is uncontrollable. This act of engagement and disengagement with the body through appropriated form of movements of the external muscle corresponds to the will of the person and which is logically intentional. The activation of the brain through one's intention can't be denied under the neuroscientific assumptions of brain activation before the intention needs further research support (e.g., Libet, 1985; Soon, Heinze, \& Haynes, 2008; Schleim, 2012; Wegner, 2002). Fox and Stein (2017) presented the case that dualism had shaped the legal domain in terms of "the intuitions about individual responsibility, wellbeing, and dignity that pervade our doctrine today" (P. 135). Since Cartesian dualism attributes mind as pure and humans have complete ownership to it, the intentions and thoughts are the property of the individuals' and it powerfully shapes the individuals will. The problem with this dualism is the conceptual error where mind and body are two separate substances and at the same time they are simultaneously operational. If law goes by this duality, the question about the intention will be unanswered as there is no way of connecting to the mechanism of the body. What drives the body or make the person act, as per the Cartesian dualism, is absurd to locate.

Activity of the body is a matter of mechanism and body design, together with the thought as something metaphysical, what Ryle (1949) situated it in the 'ghost in the machine analogy'. As discussed, free will, if not an illusion, matter in its continuity and movements, so the brain and the thought. In the criminal justice system, it is important to engage with the conceptual confusion which William James highlighted as an action-emotion continuum in which the action is interpreted as emotion. If this is true then the action of the person indulges him/her in some emotions and its interpretation in one's thought process. Moreover, it is the mechanism of action which then is passively operated by the environmental factors and then interpreted in terms of moral convention of law and society. The way Pardo and Patterson (2013) rejected dualism paradoxically makes its presence again, whether in new form of conceptual confusion or linguistic alignments to those interpretations and thought processes. Presenting the case of neuroscientists, Levy (2014) critically observed that the conceptual confusion between psychological properties and brain states doesn't imply that there are conceptual barriers in attributing the former from the latter. Though psychological properties attributed from the changing brain state theoretically doesn't gives us the ownership as per the neuroscientific logic but through the Cartesian logic psychological properties or attributes are 
the individuals space of thought process, so what govern us in the second case is our will and in the former, it is the inbuilt design of the biological being operating in the cultural context.

Whatever may be the case, in an empirical world, everything exists and real, from individuals to society to law whose foundation is based on the responsibility and accountability of human actions. People look for cause, that is their will is naturally directed towards others action and the connecting possible causes. The question is how many causes one's cognitive field may identify about the others actions and whether that person is held responsible for all the possible causes? The concatenations of causes are linked and add up to the experiences but it is difficult to figure out the final cause of particular action. We generally prefer an immediate cause (Russell, 1918) ${ }^{4}$ and avoid falling into the infinite regress or searching for the possible innumerable causes which seems to go to previous lives and destiny in some religions. Like any movie actor whom we identify with, his action towards the enemy seems to be our action. We as an observer do not act but our will against the enemy in the movie is simultaneously translated into the hero's action.

The causes behind any action of the main actor is configured into the conscious field of the observer which is also well understood by the observer that the actions which are directed towards the co-actor are taken in terms of immediate cause by the acting other in the movie. This much understanding about the main causes behind one's action is not immediately understood by the observer in the real world. For example, if in any science fiction movie, the change in the brain activations due to some neurotransmitter injection or any drug makes the actor behave erratically, the observer understands the designed causal connection but not the co-actor, in the observation of the audience in general. Here the intentions are clear in the artificial world of the movie but not in the real world. Possibly, the movie creates awareness about the possible causes leading to the behaviour but legal domain requires evidence and proper statutory understanding based on its foundational philosophy. As Kolber (2017) noted that the compatibilists interpretation of criminal law as "defendants can be punished because they can be responsible for their actions even if they are not responsible for all of the causes that make them act" (P. 10). Here the causes are giving way for the actions, so, the best possible causes are identified based on the condition under which it commonly occurs and the temporal elapse between the immediate cause and action. For legal domain time between the immediate

\footnotetext{
${ }^{4}$ Here Russell appreciated and noted the definition of cause in Baldwin dictionary as: Cause and Effect are correlative terms denoting any two distinguishable things, phases, or aspects of reality, which are so related to each other that whenever the first ceases to exist the second comes into existence immediately after, and whenever the second comes into existence the first has ceased to exist immediately before. (P. 172)

Preprint by Dr. Chetan Sinha, OP Jindal Global University, Sonipat

Email: sinchetan@gmail.com,csinha@jgu.edu.in
} 
cause identified and an action matters, in order to better reach the conclusion. These conclusions about the person's responsibility are laden with the many instances of events and time, which if we go by the physical laws can have infinite variations in between. Legal domain's conclusions, notion of right or wrong actions, responsibilities, guilty acts are defined within the boundaries of society's moral assumptions.

The notion of cause and effect depends upon the proximity or contiguity ${ }^{5}$ of both in terms of time interval and as per the human attention span allows. These conventional boundaries cater to the principle of 'same cause-same effect' imagined generally to be a scientific mechanism, which is difficult to replicate in different contexts and time. Cause and effect relationship seems to be post hoc and it became too simplistic for the legal domain to go by the past occurrence of events and the cause. In the case of neuroscientific location of cause within the brain after the occurrence of any event has witnessed series of events in different time interval ${ }^{6}$. Locating the cause on the basis of event and then predicting the same cause in the future occurrence of events seems fallacious and unaccountable to many events either not noticed or ignored as irrelevant. The importance of any cause to the event is what Russell (1918) notices as an intelligible nexus between cause and effect, which is 'familiar to imagination'. The collective imagination of people in the social system appropriates those intelligibility of the cause-effect nexus. This is not to say that cause and effect are continuous as per the societal impressions of social norms on individuals, but there are a number of moderators in the cause-effect impressions. Russell, however, showed that cause-effect relationship seems symmetrical and not an illusion. In the case of the brain of the person which is attributed to have a determining or causal effect may also be seen from the all or none principle, where once the brain activation happened leading to behaviour has already passed or occurred and then the person operated.

The cause identified for the certain behaviour can be understood as two different events, where the former and the latter have their own descriptions, and it is the certainty of the cause that led to the certainty of the effect having a more deterministic stance. Neuroscience claims about the certainty of the brain event which eventually lead to the action give additional proof to the statement of Pardo and Patterson (2013) that "free choice is not uncaused" (p. 35) where they appreciated Churchland (2006) characterisation of responsibility as 'empirical'. The advancement of different brain scanning techniques made the neuroscience observable,

\footnotetext{
${ }^{5}$ Supra 5

${ }^{6}$ Supra 6

Preprint by Dr. Chetan Sinha, OP Jindal Global University, Sonipat

Email: sinchetan@gmail.com,csinha@jgu.edu.in
} 
empirical and positivist, disclaiming anything as mind which is subjective, incongruent with language structure and lacking any perfect methodology to have an exact picture. Levy (2014) expressed his faith in neuroscience as a field which can produce reliable evidence as compared to subjective report or behaviour. Neuroscientific evidence based on the meta-theoretical assumption (e.g., determinism of Libet) of being unregulated by the will or intention of the person saturated our understanding of free will as misalignment of conceptual categories of uncontrollable to the person's responsibility. It is also noted that consciousness is an urgent factor in one's knowledge, awareness and sense of being a responsible agent. The connection of the person and not just the brain, to the context and social world. also matters as it is the person who is visible and not the brain. We have the knowledge about our and others' possession of the brain through the years of reports and images of the brain in the neurological studies, that it has occupied our consciousness of its existence in our daily discourses. Some of the scholars expressed (Midgley, 2014) that the brain is like any other organ of the body which has to function appropriately for the human to make choices. The question that often comes in our mind is 'are we really responsible for what we are and will be?' The answer is both ticklish and simple. An apt example given by William James about his grabbing a glass of water if he is thirsty. It is the person who will act to quench his thirst by going to the glass of water and not the glass of water which comes to the person to quench his thirst. This simple example explained the logic of human existence and cleared the jungle of deterministic assumptions about human choices.

In the tussle between determinists and libertarians, the balanced protagonists were compatibilists who looked for the balance between what is uncontrollable and what is wilfully possessed by the person. They looked for the truth rather than being stuck in between without any decision. For example, legalists who believed in the proper functioning of the brain to be important in rational actions. Though all the causes are undecipherable, as discussed above, it is imperative to reach out the decision rather than being indecisive. So from the deontological viewpoint the very action made sense to the legal domain even if it was done without any spurious motive, so here muddling with the cause will not undone the act. Since acts cannot be undone so the responsibility remains with the person despite the neurological deficit or injury. Morse (2004) pointed towards the brain overclaim syndrome that neuroscientists make and to be reductive with the brain in hand will not solve the problem of society where people are acting on their social world and some of their acts may not be conducive to the general social norms. It is the individual who acts in the environment despite being bombarded with the 
environmental stimuli. So, cause only matter after the action is observed. In the legal world causes of behaviour are many and uncontrollable which may nurture different kinds of acts, however, it's metatheory is both for retributivists and consequentialists, that is, to move towards precedents, and keeping check through many regulatory channels. Overall, it is the will of the person to deter from the acts not appropriated by the cultural moral codes.

\section{Everything is not determinism}

Till now, it is clear that cultural determinism is difficult to be precisely structured so that we may objectively predict its influence. However, it is also clear that cultural context is inseparably a regulatory system and individuals are not apart from it. The human agency is a cultural agency as the body of the person is buffered automatically from the cultural lens. We don't see the person as a body but as laden with some cultural ingredients that develop our self and understanding of the others self. A person inflicting injury on the others body consciously is actually a culturally laden act, and the guilt after those acts is part of that system. In this process of culturally moving and acting, the person's consciousness is universal and local at the same time. If law cares about justice, it also doesn't separate itself from the culture. Thus, the individual is not a body and all the acts are not a simple mechanism. This critical understanding of the mechanism was heavily studied and many opinions were marked on the basis of these almost concertized assumptions, that society matters and it is not completely the individual who was conceived as some body.

Thus, if any individual wished to change the conventional law, he will face the resistance from the society which created the convention and at the same time stimulating the individual to offer resistance to the imposed rules of society. This reciprocity of resistance between the individual and the society are paradoxically connected, though, it is the individual's self which contributed to the individual's freedom to resist. Law in itself is systematic, limited, and predictive, as compared to the unpredictability, indeterminacy and uncontrollability of the individuals' mind. As stated above, it is very difficult to outline all the cultural systems as it is, since, culture cannot be static and it moves with the individuals' connection to the physical, social and psychological objects in the empirical world. Though law derives its assumption from the societal moral standards, its disciplinary nature doesn't allow the intricacies in full to breach its boundary, as those complexities of stimuli are not limited, it has remarkable mathematical combinations which are difficult to model both manually and digitally. Though there is a movement to manage these rising data in the form of data management systems, still, 
it is logically clear that this is an unending process to account for all the probable combinations and to give a certain picture of the human world across the culture and in varieties of situations. It doesn't mean that law is not ready to picture those events, since it tries to capture those events and causes through different disciplinary dialogues, but at the pragmatic level its boundary especially in the grave cases of crime, is limited by the intuition and precedence. Law determines whether any act is wilfully done or not. This kind of legal boundary is the result of resolution of various debates on the meaning of free will, determinism, compatibility between the two or semi-compatibility and revisionism (see Fischer, Kane, Pereboom, \& Vargas, 2007). Though these debates are continuous and the protagonists of these stands of determined cause will also shift in their argument either to prove their past stands or in search of truth through some methodology, law brings changes to the perception of cause and assigns meaning to the 'ways of seeing' the society.

As compatibilists in different domains such as law, neuroscience, religion, natural science, psychology, sociology tried to establish a link between determinism and free will, many times they limited themselves by some established consensus. For example, in theology, the God was assumed to have an effect on the individuals, where an individual is not apart from the world created by God and even after the body perishes the soul persists and moves. One paradox which is always resolved by the theology, about the immovability of absolute and movability of the perishable in the Cartesian sense. What is immovable and permanent can have an unending effect on the body, but that requires a non-perishable existence, which is empirically not seen, as the world is perishable. Since the human/animal perishing body is an inevitable sign of change, how something immovable can have an effect. Under the theological standpoint, the creation of the soul seems for this purpose only that God is seamlessly connected to the soul and this relationship is permanent.

In the legal domain this dominant view of the religious society is not admissible and neither its logic has any substantiation. So, the free will and the deterministic stand gets limited in the empirical world and law draws the line to which humans are not apart. Neuroscience then is one of the most substantiated fields of science to be connected with the law and changing the meaning of unlimited free will and determinism. The majority of view about the methodological sophistication to understand what exactly is free will and how much it makes the person free in his/her action depends upon the exploratory perspective adopted to understand the action and responsibility of any individual or group member. The shaping of mind, environmental inputs through the group affiliations and general understanding of the 
world situates the mind into something structured. The methodological inquiries such as qualitative understanding of the individual stories and activities is the suitable exploratory move, though it is also important to make sense of structure which emerges from these inquiries and gives a concrete picture about the community or groups on which these inquiries are done. Getting the structure of free will and responsibility marks the essential feature of an individual in a group, through identifying the saturating point or point of exhaustion of the sample after which it seems nothing is new about the person or the group. This may create a vantage point on which the impression about any community or kind of individual may be anchored. Free will is not as pure and undiluted as it seems, since culture impinge on the individual sensemaking and actions which construct the notion of free will and responsibly as an embedded process, either in the language of the individual affiliated to any group or in the action directed towards the cultural artefacts. Free will is embedded in something and identification of the cause of free will may be misleading. As per the Wittgensteinianism, looking at the various cases of legal domain, it is clear that through the different testimonies, self-account and memories, free will is described and in those description the cause was identified and on the basis of which judgement was made ${ }^{7}$. The abandonment of free will in the garb of deterministic brain events or some quantum spurt of activities leading the brain to become undeterministically active, which seems to lead to human action, doesn't give an easy solution to the proponents who believe in the illusion of free will. The intelligibility of the compatibilists to situate the free will and determinism to whatever extent, seems to stands on two basic principles, first, despite being all the human and environmental factors same, how does the individual make choice, veto, make sense of alternatives, and second, to what extent the events which are not created by the individual and neither their occurrence and movements are in the conscious control of the individual, are accepted as part of the everyday activities and discourses. The will is not the same as ability or disability, as free will can be a rejection of what one is capable of doing in the favourable conditions, for example, imparting mercy despite one having the power to grant death sentence.

The criminal justice system in the past and present are not operating equivalently on the similar criteria of inferring about how much the person was responsible and acted freely and consciously (Smith, 2004; Hart, 1963, 1968). The notion about the presence of free will didn't appear at the same level in the similar kind of criminal acts. In the past societal construction of free will and morality was seen naturally to be embodied by the individuals and it was the

\footnotetext{
${ }^{7}$ Philosophical Investigation

Preprint by Dr. Chetan Sinha, OP Jindal Global University, Sonipat

Email: sinchetan@gmail.com,csinha@jgu.edu.in
} 
intuitive ${ }^{8}$ ability of the judges. The imagination about the cause of any action had the context in that spirit of time as it happens now. The rise of various tools and techniques in the modern times and the locking of imagination by something which is not considered to be metaphysical and subjective has overtaken our sensibilities in the current society. The free will of the past continued to the present where the past was seeing the person as deterministically responsible as compared to the present which is considering the person as responsibly deterministic. The thin line between the two ways of seeing the person's action is the discursive turns within the society about the taken for granted trust in the computerized techniques to know the brain. This is never to say that free will is diluted or taken as an illusion as we see through many examples that punishment for any criminal act is as rooted in the legal and social conscience as was in the past. The differences are in the metatheory which various societal institutions adopt and the kind of dialogues and debates that have largely come to the public space. So, the imagination about the cause, will and responsibility in the present seems to be more closed and confined as compared to the past. But still it is an imagination, when practically considered, it looks more pedantic and messed up with the varieties of possible evidence which may slow down the legal decision-making. However, the establishment of fast-track court looks upon the evidence rapidly and closely, as it seems, doesn't deny the possibilities of stereotypical filtering of evidence into the favour or disfavour of the defendant, as per the social and political demands. When something mysteriously regulating our behaviour becomes obvious and clear, it becomes part of our social selves and seems controllable. The view about free will is laden in the worldviews of obviousness and materialism in the current times.

\section{References}

Baxi, U. (2007). The rule of law in India. Sur, 3, São Paulo.

Berlin, I. (1999). Verification. In H. Hardy (Ed.), Isiah Berlin: Concepts and Categories: Philosophical essays. London: Pimlico.

Billig, M. (2019). More Examples, Less Theory: Historical Studies of Writing Psychology. Cambridge: Cambridge University Press

\footnotetext{
${ }^{8}$ Intuitive ability used here as an accumulation of past experiences and memories which constructs a rational picture of one's act in a social context Preprint by Dr. Chetan Sinha, OP Jindal Global University, Sonipat

Email: sinchetan@gmail.com,csinha@jgu.edu.in
} 
Churchland, P. S. (2006). Moral decision making and the brain. In J. Illes (ed.), Neuroethics:

Defining the issues in theory, practice and policy (pp. 3-16). Oxford: Oxford University Press.

De, R. (2018). A People's Constitution: The Everyday Life of Law in the Indian Republic. Princeton \& Oxford: Princeton University Press.

Fischer, J. M., Kane, R., Pereboom., \& Vargas, M. (2007). Four views on free will. Oxford: Blackwell Publishing.

Fox, D., \& Stein, A. (2017). Dualism and doctrine. In Patterson, D., and Pardo, M. S. (2017). Philosophical foundations of law and neuroscience (pp. 105-136). UK: Oxford University Press.

Fromm, E. (1964). The heart of man: Its genius for good \& evil. New York: Harper \& Colophon Books.

Fuster, J. M. (2013). The neuroscience of freedom and creativity: Our predictive brain. Cambridge University Press.

Gazzaniga, M. S. (2011). Who's in charge: Free will and the Science of the brain. UK: Robinson.

Hart, H. L. A. (1963). Law, Liberty, and Morality. Oxford: Clarendon Press. (1968).

Punishment and Responsibility: Essays in the Philosophy of Law. Oxford: Clarendon Press.

Herstein, W., Sifferd, K. L., \& Fagan, T. K. (2018). Responsible brains: Neuroscience, law and human culpability. Cambridge: The MIT Press

Jacquette, D. (2009). Philosophy of mind: The metaphysics of consciousness. London \& NewYork: Continuum.

Kolber, A. J. (2017). Free will as a matter of law. In Patterson, D., and Pardo, M. S. (2017). Philosophical foundations of law and neuroscience (pp. 9-28). UK: Oxford University Press.

Levy, N. (2014). Is neurolaw conceptually confused?. The journal of ethics, 18(2), 171-185.

Libet, B. (1985). Unconscious cerebral initiative and the role of conscious will in voluntary action. The Behavioural and Brain Sciences, 8 (4), 529-539.

Midgley, M. (2014). Do we really act? In D. Rees \& S. Rose (Eds.), The new brain sciences: Perils and Prospects (pp. 17-33). Cambridge: Cambridge University Press.

Morse, S. J. (2005). Brain overclaim syndrome and criminal responsibility: A diagnostic note. Ohio State Journal of Criminal Law, 3, 397.

Preprint by Dr. Chetan Sinha, OP Jindal Global University, Sonipat

Email: sinchetan@gmail.com, csinha@jgu.edu.in 
Pardo, M. S., and Patterson, D. (2013). Mind, brains and law: The conceptual foundations of law and neuroscience. New York: Oxford University Press.

Pickersgill, M 2013, 'The Social Life of the Brain: Neuroscience in Society. Current Sociology, 61 (3), 322-340. DOI: 10.1177/0011392113476464.

Pribram, K. H. (1973). The primate frontal cortex: Executive of the brain. In K. H. Pribram \& A. R. Luria, Psychophysiology of the frontal lobes. Academic Press.

Rose, N. (2000). The biology of culpability: Pathological identity and crime control in a biological culture. Theoretical Criminology, 4 (1), 5-34.

Russell, B. (1918). On the notion of cause. In B. Russell. Mysticism and logic (pp. 171-196). London: Penguin Books.

Ryle, G. (1949). The concept of mind. London: Penguin.

Schleim, S. (2012). Brains in context in the neurolaw debate: The examples of free will and "dangerous" brains. International Journal of Law and Psychiatry, 35, 104-111.

Smith, A. M. (2004). Human action, neuroscience and the law. In D. Rees \& S. Rose (Eds.), The new brain sciences: Perils and Prospects (pp. 103-122). Cambridge: Cambridge University press.

Soon, C. S., Brass, M., Heinze, H. J., and Haynes, J. D. (2008). Unconscious determinants of free decisions in the human brain. Nature Neuroscience, 11(5), 543-545.

Wegner, D. (2002). The illusion of conscious will. Cambridge, MA: MIT Press.

Zachar, P., \& Kendler, K. S. (2017). The Philosophy of Nosology. Annual review of clinical psychology, 13, 49-71. https://doi.org/10.1146/annurev-clinpsy-032816-045020 